University of Wollongong

Research Online

Faculty of Engineering and Information

Faculty of Engineering and Information

Sciences - Papers: Part A

Sciences

2012

Comparison of custom-moulded ankle orthosis with hinged joints and offthe-shelf ankle braces in preventing ankle sprain in lateral cutting movements

Winson Lee

University of Wollongong, ccwlee@uow.edu.au

Toshiki Kobayashi

The Hong Kong Polytechnic University

Barton Choy

The Hong Kong Polytechnic University

Aaron Leung

The Hong Kong Polytechnic University

Follow this and additional works at: https://ro.uow.edu.au/eispapers

Part of the Engineering Commons, and the Science and Technology Studies Commons

Research Online is the open access institutional repository for the University of Wollongong. For further information contact the UOW Library: research-pubs@uow.edu.au 


\title{
Comparison of custom-moulded ankle orthosis with hinged joints and off-the- shelf ankle braces in preventing ankle sprain in lateral cutting movements
}

\begin{abstract}
BACKGROUND: A custom moulded ankle orthosis with hinged joints potentially offers a better control over the subtalar joint and the ankle joint during lateral cutting movements, due to total contact design and increase in material strength. OBJECTIVES: To test the above hypothesis by comparing it to three other available orthoses. STUDY DESIGN: Repeated measures. METHODS: Eight subjects with a history of ankle sprains (Grade 2), and 11 subjects without such history performed lateral cutting movements in four test conditions: 1) non-orthotic, 2) custom-moulded ankle orthosis with hinges, 3) Sport-Stirrup, and 4) elastic ankle sleeve with plastic support. A VICON motion analysis system was used to study the motions at the ankle and subtalar joints. RESULTS: The custom-moulded ankle orthosis significantly lowered the inversion angle at initial contact $(p=0.006)$ and the peak inversion angle $(p=0.000)$ during lateral cutting movements in comparison to non-orthotic condition, while the other two orthoses did not. The three orthoses did not affect the plantarflexion motions, which had been suggested by previous studies to be important in shock wave attenuation. CONCLUSIONS: The custom-moulded ankle orthosis with hinges could better control inversion and thus expected to better prevent ankle sprain in lateral cutting movements. CLINICAL RELEVANCE: Custom-moulded ankle orthoses are not commonly used in preventing ankle sprains. This study raises the awareness of the use of custom-moulded ankle orthoses which are expected to better prevent ankle sprains.
\end{abstract}

\section{Keywords}

movements, ankle, lateral, custom-moulded, cutting, joints, hinged, braces, off-the-shelf, sprain, orthosis, preventing, comparison

\section{Disciplines \\ Engineering | Science and Technology Studies}

\section{Publication Details}

Lee, W. C. C., Kobayashi, T., Choy, B. T. S. \& Leung, A. K. L. (2012). Comparison of custom-moulded ankle orthosis with hinged joints and off-the-shelf ankle braces in preventing ankle sprain in lateral cutting movements. Prosthetics and Orthotics International, 36 (2), 190-195. 
Lee WCC, Kobayashi T, Choy BTS, Leung AKL. Comparison of custom-moulded ankle orthosis with hinged joints and off-the-shelf ankle braces in preventing ankle sprain in lateral cutting movements Prosthetics and Orthotics International. 2012, 36( 2), 190-195.

Comparison of custom-moulded ankle orthosis with hinged joints and off-theshelf ankle braces in preventing ankle sprain in lateral cutting movements

Keywords: ankle sprain, subtalar joint, inversion, braces, orthoses 


\section{ABSTRACT}

Study Design: Repeated measures.

Background: A custom moulded ankle orthosis with hinged joints potentially offers a better control over the subtalar joint and the ankle joint during lateral cutting movements, due to total contact design and increase in material strength.

Objectives: To test the above hypothesis by comparing it to three other orthoses available in the markets.

Methods: Eight subjects with a history of ankle sprains (Grade 2), and eleven subjects without such history performed lateral cutting movements in four test conditions: 1) non-orthotic, 2) custom-moulded ankle orthosis with hinges, 3) SportStirrup, and 4) elastic ankle sleeve with plastics support. A VICON motion analysis system was used to study the motions at the ankle and subtalar joints.

Results: The custom-moulded ankle orthosis significantly lowered the inversion angle at initial contact $(P=0.006)$ and the peak inversion angle $(P=0.000)$ during lateral cutting movements in comparison to non-orthotic condition, while the other two orthoses did not. The three orthoses did not affect the plantarflexion motions, which was suggested by previous studies to be important in shock wave attenuation.

Conclusions: The custom-moulded ankle orthosis with hinges could better control inversion and thus expected to better prevent ankle sprain in lateral cutting movements.

\section{Clinical Relevance}

Custom-moulded ankle orthoses are not commonly used in preventing ankle sprains. This study raises the awareness of the use of custom-moulded ankle orthoses which are expected to better prevent ankle sprains. 
Keywords: sprain, ankle, subtalar, inversion, orthosis

2022 words from Background to Conclusion 


\section{BACKGROUND}

Ankle sprain is a common injury in people involved in sports activities. Previous studies have indicated the high occurrence and recurrence rates of ankle sprain in both recreational and professional athletes ${ }^{1-4}$. While most people can get full recovery from ankle sprains after appropriate treatments, recurrent ankle sprains may cause significant disability and leave residual symptoms ${ }^{5-6}$ due to functional instability ${ }^{7}$.

Many sports activities require some rapid changes in moving directions and lateral cutting movements ${ }^{8-11}$. Inappropriate positioning of the ankle joint complex during such motions is the major cause of ankle $\operatorname{sprain}^{7,12}$. This condition occurs more frequently in people with proprioceptive deficits and ligament laxity ${ }^{13,14}$. When a foot lands in an inverted position, a high amount of inverted moment is produced at the subtalar joint producing high strain at the lateral ligament and the capsule $\mathrm{e}^{15,16}$.

Some studies suggested that an ankle orthosis significantly reduced the number of ankle sprains ${ }^{17-19}$. However, some suggested an ankle orthosis could be ineffective ${ }^{20}$, and was not as good as technical training ${ }^{21}$ in preventing ankle sprains. There is a wide variety of ankle orthoses in the market. Because there is no consistency about the effectiveness of ankle orthoses in preventing ankle sprains, the decision on which design should be used is usually based on availability and subjective perception.

Some ankle orthoses reduce inversion and eversion motions of the subtalar joint, but at the same time restrict dorsiflexion and plantarflexion motions ${ }^{22,23}$. The lack of ankle motion reduces the ability to absorb shock during landing ${ }^{24}$, leading to 
increased stresses over the knee joint ${ }^{16}$. Some utilizes strapping techniques around the ankle area, and some use foam padded, gel padded or inflatable air bladders to provide mild control over the ankle. Previous studies did not reach a consensus about their effectiveness in preventing ankle sprain ${ }^{17-20}$. Another approach is to custom make a plastics orthosis to fit to an individual person with a leg section and heel cup connected with a pair of mechanical hinges. The total contact design and the strength of the orthosis might give better control over the subtalar joint, and the hinges allow free plantarflexion and dorsiflexion motions. However, custom-moulded orthosis is not commonly used because of the extent of time and manpower involved.

This study compared among three ankle orthoses in subtalar joint motions during lateral cutting movements. It was hypothesized that the custom-moulded ankle orthosis with hinges could have better control of the subtalar joint than the inflatable air bladders and the elastic ankle sleeve with plastics support. This study recruited subjects with and without histories of ankle sprains. It was also hypothesized that people with previous history of ankle sprains would have larger ankle and subtalar joint motions when performing lateral cutting movements.

\section{METHODS}

\section{Subjects:}

This study was approved by the Human Subjects Ethics Sub-committee of Xxx Xxxx $\operatorname{Xxxx} \operatorname{Xxx} \operatorname{xxx} \operatorname{xxxx} \operatorname{Xxxxxxxxxx}$, and subjects gave informed consent to this work. Eight subjects ( $32 \pm 3$ years old; $173 \pm 6 \mathrm{~cm}$ in body height; $67 \pm 7 \mathrm{~kg}$ in body weight) with a history of ankle sprains in the past 18 months (Sprained group) were recruited. 
They had experienced an ankle sprain of Grade $2^{25}$. Another eleven subjects (32 \pm 5 years old; $172 \pm 5 \mathrm{~cm}$ in body height; $68 \pm 4 \mathrm{~kg}$ in body weight) without a history of ankle sprains in the past 5 years (Non-sprained group) also participated in this study. Table 1 shows the characteristics of each subject. All nineteen subjects were recreational athletes and did not have a history of lower extremity arthritis and fracture as well as neurological, cardiac and balance problems. They were all male so that gender effect, as reported in a previous study ${ }^{26}$, would not affect the results of this study.

\section{Orthoses and shoes:}

Three different ankle orthoses were tested: 1) custom-moulded ankle orthosis with hinges (Figure 1), 2) ${ }^{*}$ Aircast ${ }^{\mathrm{TM}}$ Sport-Stirrups, and 3) ${ }^{*} \mathrm{~A} 60^{\mathrm{TM}}$ elastic ankle sleeve with plastics support. The leg section and the heel cup of the custom-moulded orthosis were made from low-temperature thermoplastics and fitted to the subjects by an experienced orthotist. The two sections were connected by a pair of hinge joints. The Aircast ${ }^{\mathrm{TM}}$ Sport-Stirrup consisted of medial and lateral plastic bands with inner inflatable air cells that could be conformed over the malleoli. The A60 ${ }^{\mathrm{TM}}$ elastic ankle sleeve with plastics support stabilized the ankle-foot complex by tightening the elastic strap around the foot and ankle over the medial and lateral plastics supports located at both sides of the malleoli. All orthoses were fitted and checked by an orthotist before the experiment. During the experiment, standardized laboratory shoes were provided to all subjects to minimize the mechanical difference that might be caused by different shoe designs ${ }^{27}$. To allow direct attachment of the reflective markers on the foot, openings were created at the toe-box and the posterior heel counter of the shoes.

*Products of DJO Incorporated, CA, USA 


\section{Experimental tests:}

Each subject was asked to perform sideward lateral cutting movements in each of the four test conditions: 1) non-orthotic, 2) custom-moulded ankle orthosis with hinges, 3) Aircast $^{\mathrm{TM}}$ Sport-Stirrups, and 4) $\mathrm{A} 60^{\mathrm{TM}}$ elastic ankle sleeve with plastics support. The testing order was randomized. The subjects were required to shuffle laterally from a standing position for at least four steps, land into a square marked on the floor with the dominant foot, and shuffle back to their starting positions ${ }^{22}$. The entire motions were performed as fast as possible. The dominant legs of the subjects were determined by identifying the sides of the leg which kicked a ball placed in front of them. All subjects were given time to familiarize with the movement and acclimate to each orthotic condition before data collection. The time required to complete the entire movements was measured. A trial was rejected if the time required to complete the movements was not consistent with others during repeated trials. All subjects completed the movements within 10 seconds. The procedure was repeated until six successful trials were recorded with each subject for each of the three orthotic conditions. The average inversion and plantarflexion angles at initial foot contact and the peak inversion angle at the instance that the subject's foot stepped on the marked square were evaluated.

A VICON 370 motion analysis system (Oxford Metrics Ltd, Oxford, UK) was used to collect the three-dimensional kinematics data of the dominant leg of each subject. Six infrared-emitting cameras capturing 60 frames per second were used. Reflective markers of $25 \mathrm{~mm}$ in diameters were attached to the lateral and medial malleoli, fibular head, tibial tuberosity, heel, as well as the first and the fifth metatarsal heads ${ }^{23}$. 
Six infrared-emitting cameras, with a sampling frequency of 60 frames per second were used to capture the image. The three-dimensional joint kinematics between each lower limb segment was calculated using Euler's rotation theory ${ }^{28}$.

\section{Statistical analyses:}

One-way repeated measures ANOVA was performed to study if significant difference exists among the four testing conditions in both the Sprained and the Non-sprained groups. Post-hoc Bonferoni tests were subsequently performed to compare each testing condition. To study if there is any significant difference between the Sprained group and the Non-sprained group, independent t-test was performed independently in each of the four test conditions. The level of significance was set at $\alpha=0.05$. When performing multiple comparisons among the four testing conditions, Bonferoni correction was performed adjusting $\alpha$ to be 0.008 .

\section{RESULTS}

Figure 2 shows the typical changes in inversion angles when the dominant foot stepped on the marked stance during the lateral cutting movement. As the subjects shuffled laterally, the foot was inverted throughout the entire stance time and the inversion angles had two peaks. The mean and standard deviation values at the initial floor contact and the peak comparing the four test conditions are shown in Table 2. The custom moulded ankle orthosis significantly lowered the inversion angle at initial contact as compared to the non-orthotic condition in both the Sprained $(P=0.004)$ and Non-sprained group ( $P=0.006)$. The custom-moulded ankle orthosis with hinges also

significantly lowered the peak inversion angle, when compared to the Aircast ${ }^{\mathrm{TM}}$ 
Sport-Stirrups, the $\mathrm{A} 60^{\mathrm{TM}}$ elastic ankle sleeve with plastics support as well as the non-orthotic condition in Sprained $(P=0.000)$ and Non-sprained groups $(P=0.000)$.

The Sport-Stirrup and the elastic ankle sleeve with plastics support did not produce statistical difference in the inversion angle at initial contact and the peak inversion angle, when compared to the non-orthotic condition. Although the plantarflexion angle was in average the lowest in the Sprained group when using the custom moulded ankle orthosis, the differences in plantarflexion angles were not statistically significant among all the four test conditions.

Although the inversion and plantarflexion angles at initial contact as well as the peak inversion angles of the Sprained group were in average higher than the Non-sprained group in each of the test condition, the difference did not reach a statistical significance. Larger standard deviations were noted in plantarflexion angles. These suggested that various strategies in positioning the plantarflexion/dorsiflexion angles during initial contacts were used among different subjects.

\section{DISCUSSION}

Previous studies ${ }^{15,30,31}$ identified the importance of controlling inversion in preventing ankle sprain. This study looked into the amount of control of three different ankle orthoses over the subtalar and ankle joints. Lateral cutting movements were investigated as uncontrolled inversion during such movements producing ankle sprains commonly occurs ${ }^{15}$. It was showed that a custom-moulded ankle orthosis with hinges significantly reduced the inversion angle, while the Sport-Stirrup and the elastic ankle sleeve with plastics support did not. It suggested that the hinged ankle 
orthosis might outperform the two other orthoses in preventing ankle sprains during lateral cutting movements on smooth floor surfaces. More studies, however, are required to compare these orthoses in real sports activities.

Better control of the subtalar joint by custom moulded ankle orthoses can be explained by the higher stiffness of the material used. The custom moulding of the heel cup and the leg section also enabled well fit and total contact. The orthosis did not restrict plantarflexion motions, thanks to the introduction of the hinge joints, which was suggested to be important in shock absorption ${ }^{16}$. Hinge joints could add prices, fabrication time, and overall weight. To confirm that the hinge joints are necessary, the hinged orthoses can be compared to non-hinged custom-moulded orthoses in future studies. While previous studies were inconsistent in determining the effectiveness of off-the-shelf ankle orthoses ${ }^{17-19,20-21,32}$, this study provides objective information to show that the custom moulding and incorporation of a hinged joint would likely improve preventive outcomes.

The custom-moulded approach is not commonly used in treating sprained ankle because of the time and manpower involved. However, with the objective information provided in this study, this approach should be re-considered. Further investigations are suggested in the choice of materials for the provision of lighter and more comfortable design so that the users need not sacrifice their performances with the intervention. Large contact area between the skin and the orthosis and relief over the bony prominence such as the malleoli could provide better comfort. This study was conducted in a gait laboratory in which the ground condition was different from the actual ground conditions in sports activities. Future studies can also include 
investigations of different orthotic designs different ground conditions and sports activities.

The specific aim of this study was to study the effectiveness of three kinds of ankle orthoses to control ankle and subtalar joint motions during lateral cutting movements. Ground reaction forces were not investigated in this study. However, the effects of ankle orthoses on mediolateral forces were investigated by other researchers ${ }^{33-34}$, however, contradictory results were obtained. A direct relationship between ground reaction forces and ankle sprains has not yet been identified.

\section{CONCLUSION}

This study compared the effecitiveness of three different ankle orthoses in controlling ankle and subtalar motions when the subjects were performing lateral cutting movements. It was found that a custom-moulded ankle orthosis with hinges significantly reduced the inversion and plantarflexion angles, and the other two ankle orthoses did not. While previous studies have well documented the importance of controlling inversion, based on better control of the undesired inversion in lateral cutting movements, it is expected that a custom-moulded ankle orthosis with hinges could be more effective in preventing ankle sprain comparing to the using of SportStirrup and the elastic ankle sleeve with plastics support.

\section{Declaration of Conflicting Interests}

None declared 


\section{REFERENCES}

1. Beynnon BD, Renstrom PA, Alosa DM, Baumhauer JF, Vacek PM. Ankle ligament injury risk factors: a prospective study of college athletes. J Orthop Res 2001;19:213-20.

2. Bridgman SA, Clement D, Downing A, Walley G, Phair I, Maffulli N. Population based epidemiology of ankle sprains attending accident and emergency units in the west midlands of England, and a survery of UK practice for severe ankle sprains. Emer Med $J$ 2003;20:508-10.

3. Yeung MS, Chan KM, So CH, Yuan WY. An epidemiological survey on ankle sprain. Bri J Sport Med 1994;28:112-6.

4. Waterman BR, Owens BD, Davey S, Zacchilli MA, Belmont PJ. The epidemiology of ankle sprains in the United States. J Bone Joint Surg Am. 2010;92:2279-84.

5. Malliaropoulos N, Ntessalen M, Papacostas E, Longo UG, Maffulli N. Reinjury after acute lateral ankle sprains in elite track and field athletes. Am J Sports Med 2009 $37: 1755-61$

6. Swenson DM, Yard EE, Fields SK, Comstock RD. Patterns of recurrent injuries among US high school athletes, 2005-2008. Am J Sports Med 2009 37:1586-93.

7. Wright IC, Neptune RR, Bogert AJVD, Nigg BM. The influence of foot positioning on ankle sprains. J Biomech 2000;22:513-9.

8. Brukner P, Khan K. Clinical Sports Medicine. $2^{\text {nd }}$ Ed. McGraw-Hill Companies Inc. $2001 ; 558-9$

9. Stuessi A, Stacoff A, Tiegermann V. Rapid sideward movements in tennis. In: Segesser 
B, Pforringer W(eds). The shoe in sport. Chicago, IL, Year Book Medical 1989:53-62.

10. Sacco IC, Takahasi HY, Suda EY, Battistella LR, Kavamoto CA, Lopes JA,Vasconcelos JC. Ground reaction force in basketball cutting maneuvers with and without ankle bracing and taping. Sao Paulo Med J 2006;124:245-52.

11. Eils E, Streyl M, Linnenbecker S, Thorwesten L, V Valker K, Rosenbaum D. Characteristic plantar pressure distribution patterns during soccer-specific movements. Am J Sports Med. 2004;32:140-5.

12. Robbins S, Waked E, Rappel R. Ankle taping improves proprioception before and after exercise in young men. Brit J Sport Med 1995;4:242-7.

13. Lentell G, Baas B, Lopez D, McGuire L, Sarrels M, Snyder P The contributions of proprioceptive deficits, muscle function, and anatomic laxity to functional instability of the ankle. J Orthop \& Sport Phy Ther 1996;21:206-15.

14. Santos MJ, Liu W. Possible factors related to functional ankle instability. J Orthop Sports Phys Ther 2008;38:150-7.

15. Garrick, JG. The frequency of injury, mechanism of injury, and the epidemiology of ankle sprains. Am J Sport Med 1977;5, 241-2.

16. Mccaw ST, Cerullo JF. Prophylactic ankle stabilizers affect ankle joint kinematics during drop landings. Med Sci Sport Exer 1999;31:702-7.

17. Stasinoponlos D. Comparison of three preventive methods in order to reduce the incidence of ankle inversion sprains among female volleyball players. Brit J Sport Med 2004;38:182-5. 
18. Sharpe SR, Knapik J, Jones B. Ankle braces effectively reduce recurrence of ankle sprains in female soccer players. J Athletic Training 1997;32:21-24.

19. Pedowitz DI, Reddy S, Parekh SG, Huffman GR, Sennett BJ. Prophylactic bracing decreases ankle injuries in collegiate female volleyball players. Am J Sports Med 2008 36:324-7.

20. Mohammadi F. Comparison of 3 preventive methods to reduce the recurrence of ankle inversion sprains in male soccer players. Am J Sports Med 2007;35:922-6.

21. Stasinopoulos D. Comparison of three preventive methods to reduce the incidence of ankle inversion sprains among female volleyball players. Br J Sports Med 2004;2:182-5.

22. Gudibanda A, Wang YT. Effect of the ankle stabilizing orthosis on foot and ankle kinematics during cutting maneuvers. Res Sport Med 2005;13:111-26.

23. Simpson KJ, Cravens S, Higbie E, Theodorou C, DelRey P. A comparison of the sport stirrup, malleoloc and swede-o ankle orthoses for the foot-ankle kinematics of a rapid lateral movement. Int J Sport Med 1999;20:396-402.

24. Riemann BL, Schmitz RJ, Gale M, McCaw ST. Effect of ankle taping and bracing on vertical ground reaction forces during drop landings before and after treadmill jogging. $J$ Orthop Sport Phy Ther 2002;32:628-35.

25. Wolfe MW, Uhl TL, Mattacola CG, Mccluskey LC. Mangement of ankle sprains. Am Fam Physician 2001;63:93-105.

26. Decker MJ, Torry MR, Wyland DJ, Sterett WI, Steadman JR. Gender differences in lower extremity kinematics, kinetics and energy absorption during landing. Clin Biomech 2003;18:662-9. 
27. Stacoff A, Steger J, Stussi E, Reinschmidt C. Lateral stability in sideward cutting movements. Med Sci Sport and Exer 1996;28:350-8.

28. Areblad M, Nigg BM, Ekstrand J, Olsson O, Ekstrom H. Three dimensional measurement of rearfoot motion during walking. J Biomech 2001;23: 993-40.

29. Frey C, Feder KS, Sleight J. Prophylactic ankle brace use in high school volleyball players: a prospective study. Foot Ankle Int 2010;31:296-300.

30. Nishikawa T, Grabiner MD Peroneal motor neuron excitability increases immediately following application of a semirigid ankle brace. J Orthop Sport Phy Ther 1999;29:168176.

31. Wiley JP, Nigg BM. The effect of an ankle orthosis on ankle range of motion and performance. J of Orthop Sport Phy Ther 1996;23:362-9

32. Dizon JM, Reyes JJ. A systematic review on the effectiveness of external ankle supports in the prevention of inversion ankle sprains among elite and recreational players. J Sci Med Sport 2010;13:309-17.

33. Cloak R, Galloway S, Wyon M. The effect of ankle bracing on peak mediolateral ground reaction force during cutting maneuvers in collegiate male basketball players. $J$ Strength Cond Res 2010;24:2429-33.

34. Cordova, ML, Armstrong, CW, Rankin, JM, and Yeasting, RA.Ground reaction forces and EMG activity with ankle bracing during inversion stress. Med Sci Sports Exerc 1998;30:1363-70. 


\section{List of tables}

Table 1. Subject characteristics (Sprained group: subject number 1-7; Non-sprained group: subject number 8-18)

Table 2: Comparison of mean plantarflexion/inversion angles and peak inversion in four test conditions and two subject groups performing lateral cutting movements. 
Table 1. Subject characteristics (Sprained group: subject number 1-7; Non-sprained group: subject number 8-18)

\begin{tabular}{|l|l|l|l|l|}
\hline Subject number & Age (year) & Body height $(\mathrm{cm})$ & Body weight $(\mathrm{kg})$ & Dominant side \\
\hline 1 & 20 & 176 & 67 & Right \\
\hline 2 & 44 & 165 & 66 & Right \\
\hline 3 & 34 & 172 & 74 & Right \\
\hline 4 & 30 & 165 & 62 & Right \\
\hline 5 & 30 & 170 & 70 & Left \\
\hline 6 & 35 & 179 & 65 & Left \\
\hline 7 & 30 & 172 & 69.5 & Right \\
\hline 8 & 30 & 176 & 68 & Right \\
\hline 9 & 29 & 171 & 63.5 & Right \\
\hline 10 & 34 & 171 & 70 & Right \\
\hline 11 & 30 & 178 & 72.5 & Right \\
\hline 12 & 30 & 182 & 66 & Right \\
\hline 13 & 33 & 166 & 62 & Right \\
\hline 14 & 32 & 174 & 72 & Right \\
\hline 15 & 38 & 165 & 55 & Right \\
\hline 16 & 29 & 170.5 & 76.5 & Right \\
\hline 17 & 30 & 173 & 70.5 & Right \\
\hline 18 & 34 & 177 & 67 & Right \\
\hline Average & 32 & 172 & 68 & Right: 16 / Left: 2 \\
\hline
\end{tabular}


Table 2. Comparison of mean plantarflexion and inversion angles (degrees) in four test conditions and two subject groups performing lateral cutting movements.

\begin{tabular}{|c|c|c|c|c|c|}
\hline \multirow{2}{*}{$\begin{array}{c}\text { Test } \\
\text { parameters }\end{array}$} & \multirow{2}{*}{$\begin{array}{l}\text { Subject } \\
\text { group }\end{array}$} & \multicolumn{4}{|c|}{ Types of orthoses } \\
\hline & & $\begin{array}{l}\text { Custom- } \\
\text { moulded }\end{array}$ & $\begin{array}{c}\text { Elastic ankle } \\
\text { sleeve }\end{array}$ & Sport-Stirrup & Non-orthotic \\
\hline \multirow{2}{*}{$\begin{array}{l}\text { Inversion angles } \\
\text { at initial contact } \\
\text { Mean(s.d.) }\end{array}$} & $\begin{array}{l}\text { Sprained } \\
\text { Group }\end{array}$ & *15.0 (6.9) & $16.7(7.8)$ & $17.0(6.8)$ & *18.9 (6.6) \\
\hline & $\begin{array}{l}\text { Non-Sprained } \\
\text { Group }\end{array}$ & *13.8 (5.2) & $15.7(5.1)$ & $15.5(4.2)$ & *15.8 (6.2) \\
\hline \multirow{2}{*}{$\begin{array}{l}\text { Peak inversion } \\
\text { angles } \\
\text { Mean(s.d.) }\end{array}$} & $\begin{array}{l}\text { Sprained } \\
\text { Group }\end{array}$ & ${ }^{*,+, \wedge} 32.5(9.7)$ & *37.8 (7.9) & ${ }^{+} 36.2(7.2)$ & $38.1(7.1)$ \\
\hline & $\begin{array}{l}\text { Non-Sprained } \\
\text { Group }\end{array}$ & ${ }^{*,+, \wedge} 30.8(4.9)$ & $34.5(4.6)$ & ${ }^{+} 36.0(5.9)$ & ${ }^{\lambda} 36.4(5.6)$ \\
\hline \multirow{2}{*}{$\begin{array}{l}\text { Plantarflexion } \\
\text { angles at initial } \\
\text { contact } \\
\text { Mean(s.d.) }\end{array}$} & $\begin{array}{l}\text { Sprained } \\
\text { Group }\end{array}$ & $8.3(5.9)$ & $10.1(6.1)$ & $11.5(5.3)$ & $10.0(10)$ \\
\hline & $\begin{array}{l}\text { Non-Sprained } \\
\text { Group }\end{array}$ & $6.8(12.1)$ & $7.1(12.7)$ & $2.6(9.5)$ & $7.8(14.2)$ \\
\hline
\end{tabular}

In comparing the four orthotic conditions, a pair of symbols of ${ }^{*},{ }^{+}$, and ${ }^{\wedge}$ in a row indicated a statistical difference $(\mathrm{p}<0.05)$.

No significant difference was found when comparing the three test parameters between the Sprained and the Non-Sprained group. 


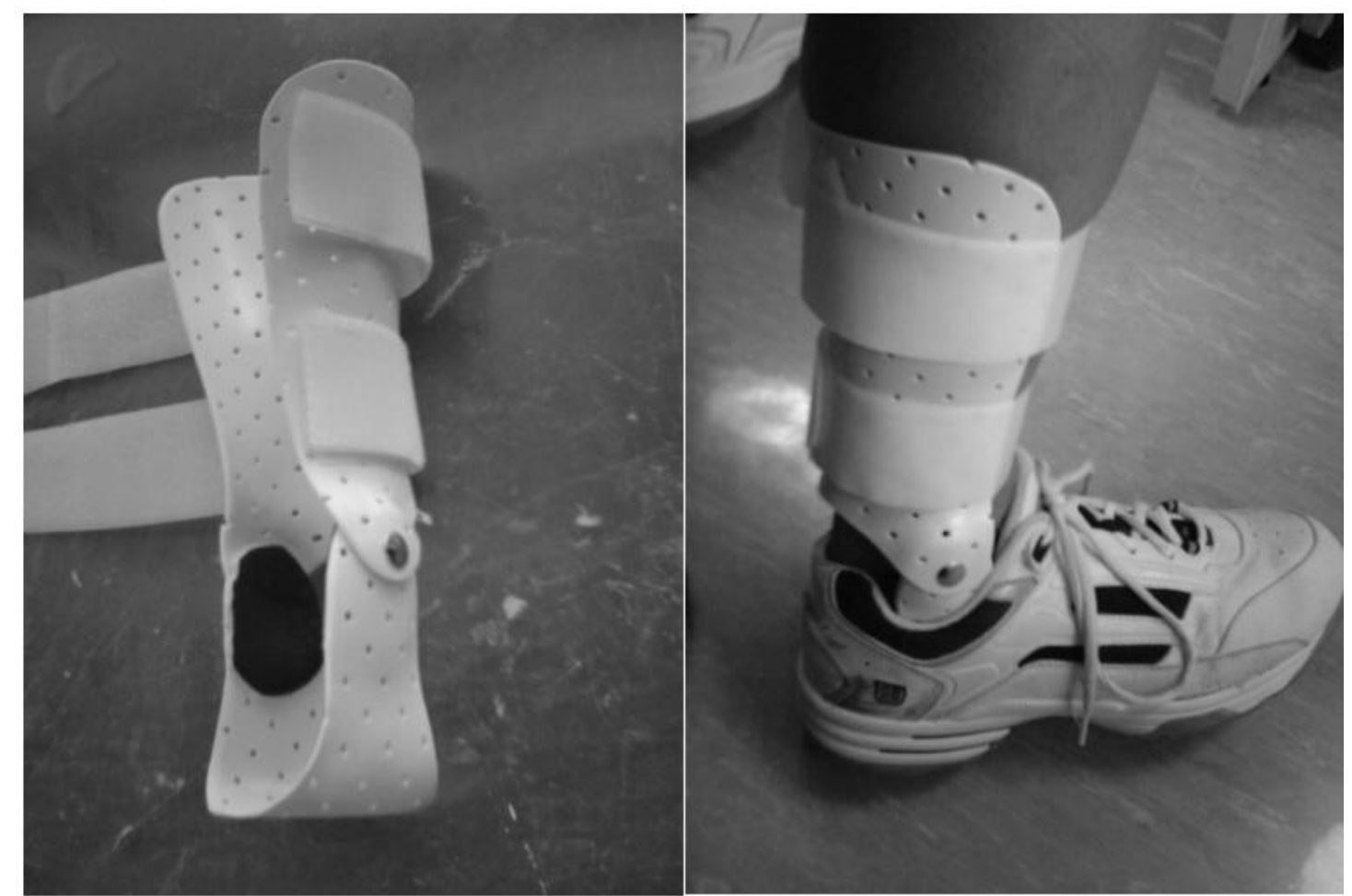

Figure 1. The custom-moulded and hinged ankle orthosis 


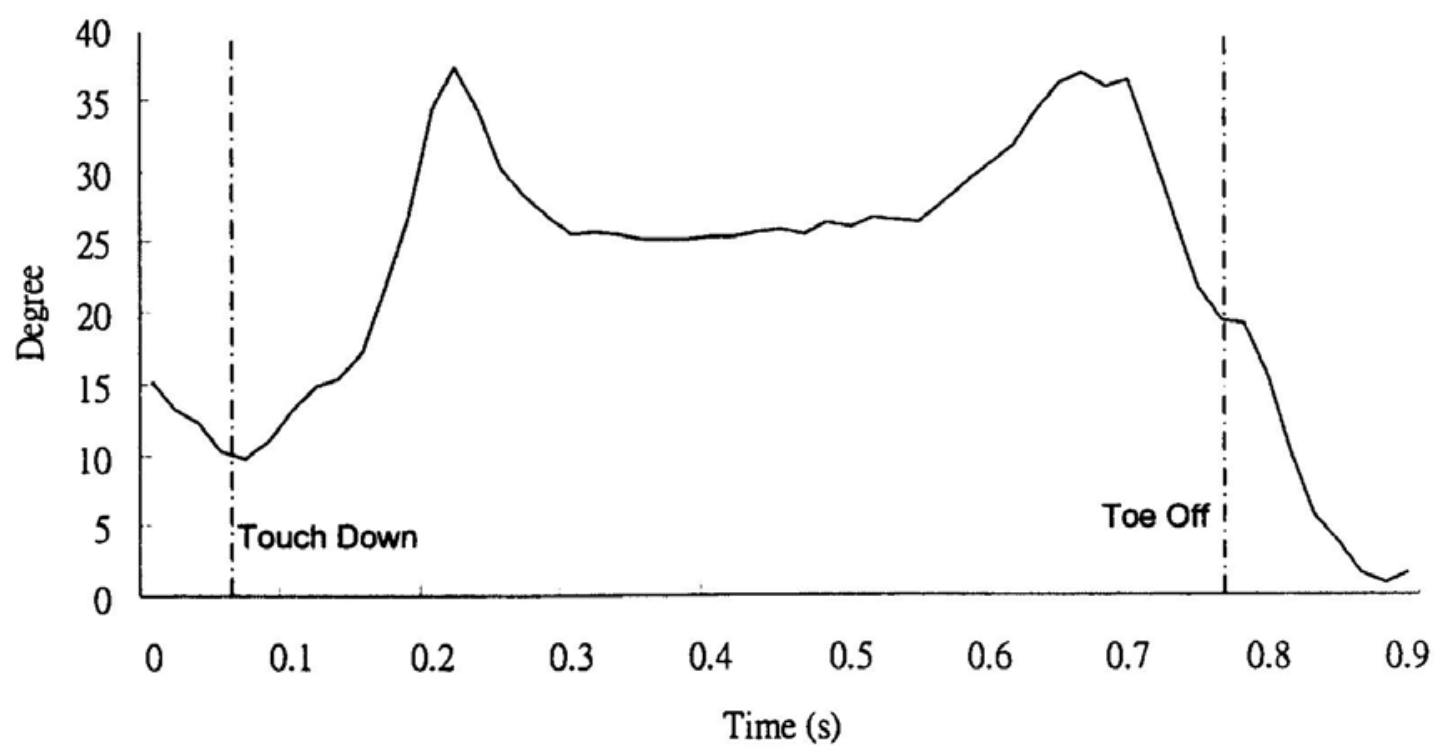

Figure 2. Typical changes in inversion angles in one complete stance during the lateral cutting movement 